\title{
Convenient and rapid synthesis of 3-selenocyanato-4H-chromen-4-ones.
}

\author{
Anne Roly Obah Kosso, \\ Julie Broggi, \\ Sébastien Redon,* \\ Patrice Vanelle* \\ Aix Marseille Univ, CNRS, ICR Institut de Chimie Radicalaire, \\ UMR 7273, Equipe Pharmaco-Chimie Radicalaire (LPCR), \\ Faculté de Pharmacie, 27 Boulevard Jean Moulin CS-30064, \\ 13385 Marseille Cedex 05, France. \\ sebastien.redon@univ-amu.fr \\ patrice.vanelle@univ-amu.fr
}<smiles>[R]#CC=C(C)C(C)=O</smiles>

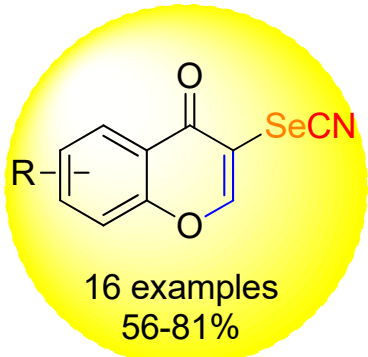

chromatography-free inexpensive reagents

Abstract A sequential one pot, simple and convenient method is described for the synthesis of 3-selenocyanato-4H-chromen-4-ones by addition first of DMF-DMA then of triselenodicyanide as electrophile.

Key words Selenocyanate, Chromones, Triselenodicyanide, Selenium dioxide, Malononitrile, Electrophile Addition, Oxidation, Rearrangement.

Organic selenocyanates (RSeCN) interest medicinal chemists because of for their remarkable activities as antileishmanial ${ }^{1}$ and cancer chemopreventive agents. ${ }^{2}$ The chemical field has known organo selenocyanates for almost a century, but recent advances led to a revival of interest in these compounds. Compared to the arylselanyl group, the SeCN functional group offers the advantage of being an air- and moisture-stable intermediate. They behave like pseudohalides, where the $\mathrm{CN}$ acts as a leaving group. ${ }^{\text {a-c }}$ They can also be transformed by base- or $\mathrm{NaBH}_{4}$-mediated decyanation. ${ }^{3 \mathrm{~d}}$ For the selenocyanation of electron-rich arenes, potassium selenocyanate ( $\mathrm{KSeCN}$ ) is typically used as radical source with an oxidant such as cerium ammonium nitrate ${ }^{4 \mathrm{a}}$ or $\mathrm{K}_{2} \mathrm{~S}_{2} \mathrm{O}_{8}$, ${ }^{4 \mathrm{~b}}$ or as an electrophilic source with $\mathrm{N}$-iodosuccinimide ${ }^{4 \mathrm{c}}$ or $\mathrm{N}$-chlorosuccinimide ${ }^{4 \mathrm{~d}}$. The disadvantage with most of these methods is that they require odorous, airsensitive and expensive potassium selenocyanate, along with tedious product purification by column chromatography.

Developing a more attractive industry-compatible process requires a straightforward, odorless, inexpensive and scalable method. Triselenodicyanide $\left(\mathrm{Se}(\mathrm{SeCN})_{2}\right)$ represents an ideal electrophilic source, ${ }^{5}$ especially considering its simple and cheap generation from malononitrile and odorless selenium dioxide. So far, this reagent has only been employed for the direct selenocyanation of activated nitrogen-containing heterocycles (indoles ${ }^{6 a}$ and imidazoheterocycles ${ }^{6 b}$ ). In continuation of our research centered on efficient one pot synthesis, ${ }^{6 c}$ we investigated the reactivity of triselenodicyanide in a one pot two-step procedure for the selenocyanation of chromones from $o$-hydroxyacetophenones. Chromone structures, widely found in many natural products, are valued in pharmacology notably for their antiallergic, anti-inflammatory, antidiabetic, antitumoral, and antimicrobial properties. ${ }^{7}$ We hypothesized that combining selenocyanates with chromones could enhance these biological properties. Selenation for chromones has so far only concerned the introduction of arylselanyl groups ${ }^{8}$ in the C3-position; to our knowledge, no C3-selenocyanation has been performed to date.

To validate the sequential one pot procedure, we first optimized the insertion of the dimethylamino group to activate the enaminones (2a) ${ }^{9}$ thus-formed for the subsequent addition of the electrophilic selenocyanate. The $o$-hydroxyacetophenone (1a) was heated with different equivalents of $N, N$-dimethylformamide dimethyl acetal (DMF-DMA) under neat conditions at temperatures ranging from 80 to $120^{\circ} \mathrm{C}$; and the reaction monitored by LC-MS. The best result was obtained at $100^{\circ} \mathrm{C}$ for 2 hours with 1 equiv. of DMF-DMA. We then explored the electrophilic addition of triselenodicyanide without prior isolation of the intermediate. Using a previously optimized solvent system (DMSO, 1 mol. $\mathrm{L}^{-1}$ ), ${ }^{6 \mathrm{~b}}$ we tested different amounts of $\mathrm{SeO}_{2}$ and malononitrile at room temperature for 1 hour (Table 1, entries 1-4). With a $\mathrm{SeO}_{2} /$ malononitrile proportion of $1 / 0.5$, low conversion of $\mathbf{1 a}$ was obtained (31\%). Moderate conversion was obtained with a proportion of 2/1 (entry 2). Surprisingly, increasing the amount of malononitrile decreased the conversion, probably due to the formation of unreactive selenium-based intermediate. An excellent NMR conversion was obtained with $\mathrm{SeO}_{2} /$ malononitrile proportion of 3/1 after only $30 \mathrm{~min}$ at r.t. (entry 4). Addition of 3 volumes of water precipitated the pure selenocyanated product to give $76 \%$ yield. Lower conversion was obtained when the reaction was conducted with dry DMSO under nitrogen atmosphere, probably due to lower $\mathrm{SeO}_{2}$ solubility in the absence of water (entry 5). 


\begin{tabular}{|c|c|c|c|}
\hline $1 a$ & $\underset{0^{\circ} \mathrm{C}, 2 \mathrm{~h}}{\longrightarrow}$ & 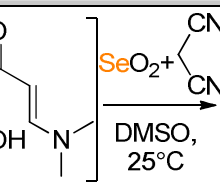 & $\mathrm{O}_{1}^{\mathrm{O}}$ \\
\hline Entry & $\mathrm{SeO}_{2}$ (equiv.) & Malononitrile (equiv.) & Yield (\%) \\
\hline 1 & 1 & 0.5 & 31 \\
\hline 2 & 2 & 1 & 72 \\
\hline 3 & 2 & 2 & 39 \\
\hline 4 & 3 & 1 & $100(76)^{c}$ \\
\hline 5 & 3 & 1 & $78^{d}$ \\
\hline
\end{tabular}

a) Reaction conditions: o-hydroxyacetophenone $1 \mathrm{a}\left(0.5 \mathrm{mmol}, 1\right.$ equiv.), DMF-DMA (1 equiv.) at $100^{\circ} \mathrm{C}$ for $2 \mathrm{~h}$. Then a pre-prepared solution of SeO $\mathrm{O}_{2}$ and malononitrile in DMSO $(0.5 \mathrm{~mL})$ at $25^{\circ} \mathrm{C}$ for $20 \mathrm{~min}$ was added under air atmosphere. The reaction mixture was stirred for a further $1 \mathrm{~h}$. b) ${ }^{1} \mathrm{H}$ NMR yield of 3 a (isolated yield).

c) 30 min. d) with dry DMSO under nitrogen atmosphere.

Next, we examined the scope of our selenocyanation method with variously decorated $o$-hydroxyacetophenones (Scheme 1).10

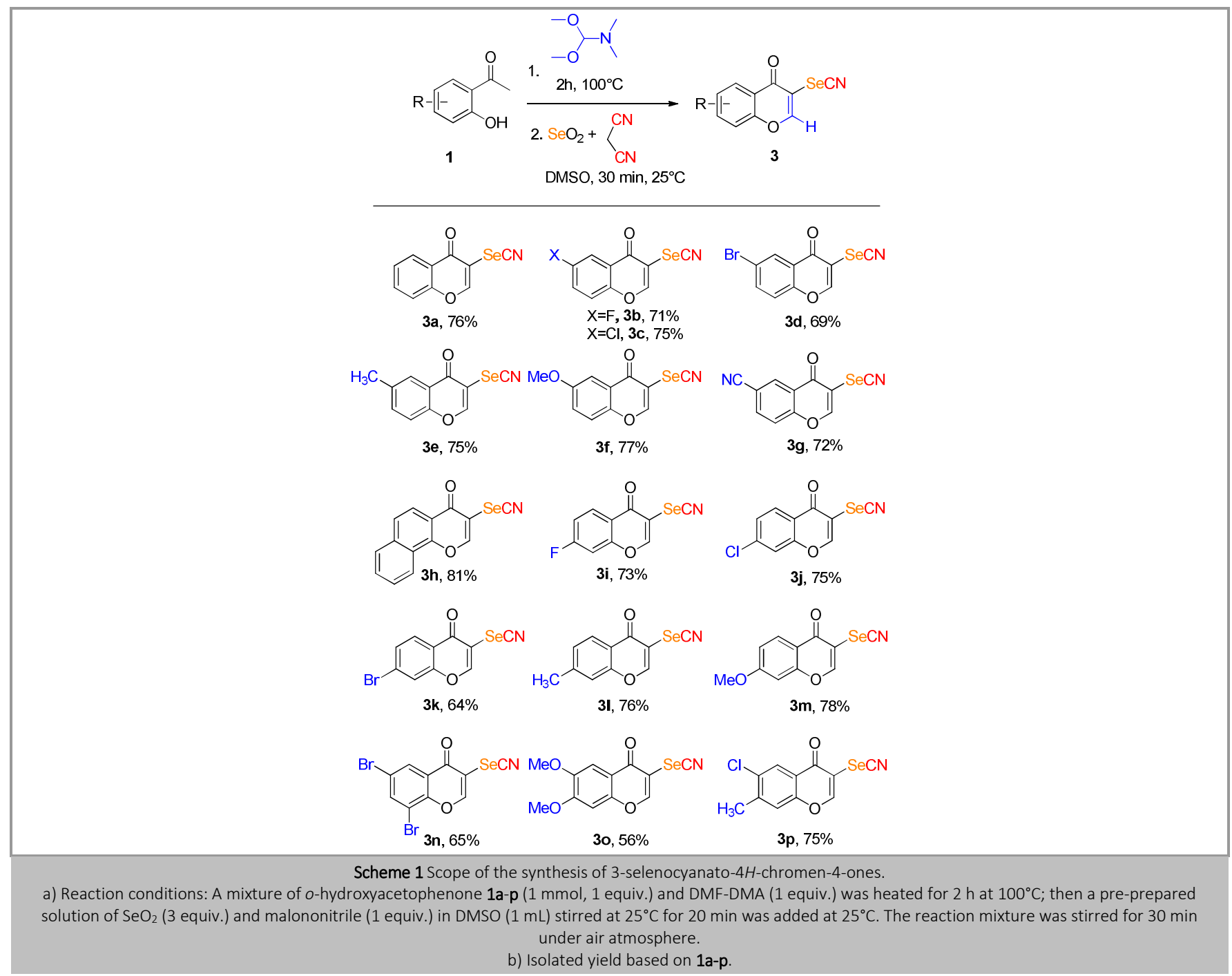

The selenocyanation led to good yields and tolerated numerous functional groups such as halogen (3b, 3c, 3d, 3i, 3j, 3k), methyl (3e, 31), alkoxy (3f, 3m) or nitrile groups (3g). Both electron-rich and -deficient substituents were well tolerated. Only the $o$ hydroxyacetophenone bearing a $\mathrm{NO}_{2}$ group at the para-position of the phenol did not react. The relative positioning of the substituent on the aromatic ring (ortho, meta- or para-position) did not affect the efficiency of the reaction. Replacing the phenyl moiety by a naphthalene led to a better yield of 3-cyanoselenatochromone (3h, 81\%). In contrast, the yield in presence of two hydrophilic substituents (two methoxy) was moderate (3o, 56\%).

To further explore the applicability of the procedure, we performed a gram-scale synthesis of (3a) with $10 \mathrm{mmol}$ of $o$ hydroxyacetophenone. This reaction was accomplished with a slight increase in yield (79\%) without changing reaction time (scheme 2). 


$\mathbf{1 a}(1.36 \mathrm{~g}, 10 \mathrm{mmol})$

We suggest the following mechanism to explain our experimental results (scheme 3). First, the $o$-hydroxyacetophenone (1a) is converted into the enaminone (2a) with DMF-DMA. Meanwhile, the reaction between 3 equiv. of selenium dioxide and 1 equiv. of malononitrile gives the triselenodicyanide (4). ${ }^{\text {a }}$ The enaminone (2a) reacts on the most electrophilic selenium of (4) atom, leading to an iminium salt. Cyclization with phenol may occur, leading to a new iminium salt. After elimination of the volatile dimethylamine, the 3selenocyanato-4H-chromen-4-one (3a) is isolated.

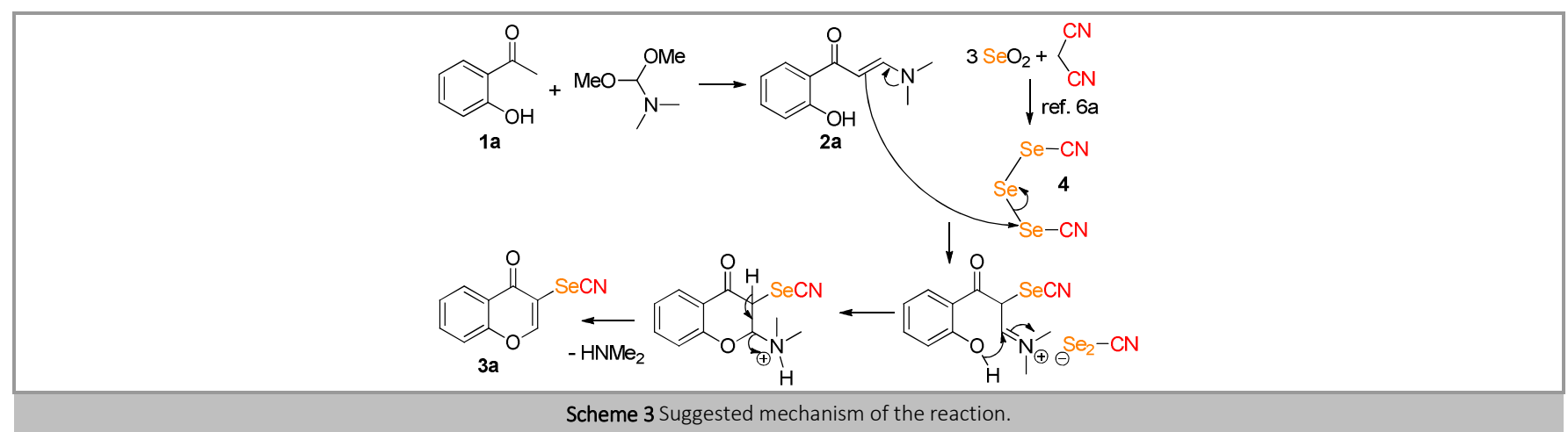

To demonstrate the utility of the selenocyanated chromones, two transformations of the SeCN functional group were explored (Scheme 4). The 3-selenocyanato-4H-chromen-4-one (3a) was converted into (5a) bearing a seleno ester group in $80 \%$ yield via a reduction with $\mathrm{NaBH}_{4}$ into a selenolate followed by addition of an electrophile (acetyl chloride). The chromen-4-one (3a) was then subjected to $\mathrm{H}_{2} \mathrm{O}_{2}$ oxidation (1 equiv.) in dichloromethane. To our surprise, no selenoxide was isolated; instead only unexpected $o$ hydroxybenzoic acid appeared. The reaction was not complete even after one day at room temperature. Adding 3 equiv. of $\mathrm{H}_{2} \mathrm{O}_{2}$, allowed complete conversion into $o$-hydroxybenzoic acid with a $76 \%$ yield.

Scheme 4 ransformations of the selenocyanated group in $5 \mathrm{a}$ and $6 \mathbf{6}$.

Assuming that the chromone first lost the double bond and the SeCN group and that the ketone was secondly converted into carboxylic acid, a cascade reaction of several oxidations and rearrangements could be involved. The proposed mechanism is based on previous studies on the oxidative rearrangement of selenium (scheme 5). ${ }^{11}$ The selenocyanate group could first be oxidized by $\mathrm{H}_{2} \mathrm{O}_{2}$ into selenoxide species. A polarizable double bond further oxidized would be easily convertible into epoxide by $\mathrm{H}_{2} \mathrm{O}_{2}$. Then addition of water on position 2 could open this activated epoxide, inducing the expulsion of "HOSeCN". HOSeCN could then be further oxidized by the excess of $\mathrm{H}_{2} \mathrm{O}_{2}$ into $\mathrm{CNSe}(\mathrm{O}) \mathrm{OOH}$ (cyanoperseleninic acid). Perseleninic acid is know as a selective oxidant able to perform BaeyerVilliger reactions. ${ }^{12}$ The Baeyer-Villiger oxidation of the diketone could give the acid anhydride derivative. The hemiacetal formed upon opening of the seven-membered ring could expulse the oxoacetic acid and the $o$-hydroxybenzoic acids in the presence of water. The requirement of four equivalents of $\mathrm{H}_{2} \mathrm{O}_{2}$ for complete reaction is in agreement with the mechanism described. These successive oxidation steps demonstrate that these chromone-4-ones with a selenium on position 3 could be compounds of interest due to their antioxidant properties. 


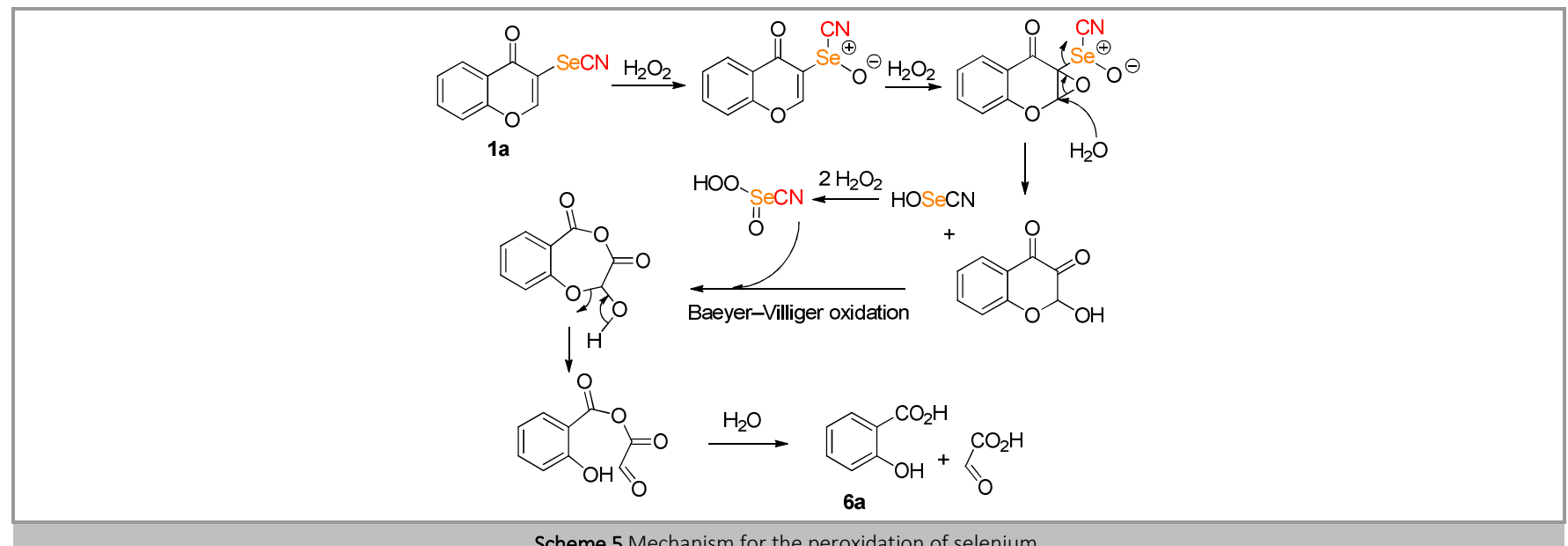

In summary, we have developed an efficient approach for the preparation of 3-selenocyanato- $4 H$-chromen-4-ones using readily available selenium dioxide and 2-hydroxyacetophenones. This one pot two-step reaction led to good yields with easy purification by simple filtration. The method uses odorless and inexpensive starting materials. Oxidation of the core of the chromones gave the $o$ hydroxybenzoic acid by rearrangement of the selenium. This result indicates that insertion of SeCN in position 3 of chromones could increase their antioxidant properties.

\section{Funding Information}

Aix-Marseille Université and the Centre National de la Recherche Scientifique (CNRS) are gratefully acknowledged for financial support. A. R. Obah Kosso thanks OGES-Congo for her PhD grant.

\section{Acknowledgment}

We warmly thank Vincent Remusat and the Spectropole (http://www.spectropole.fr) for NMR and HRMS analysis.

\section{References and Notes}

(1) (a) Baquedano, Y.; Moreno, E.; Espuelas, S.; Nguewa, P.; Font, M.; Gutierrez, K. J.; Jiménez-Ruiz, A.; Palop, J. A.; Sanmartín, C. Eur. J. Med. Chem. 2014, 74, 116. (b) Baquedano, Y.; Alcolea, V.; Toro, M. A.; Gutierrez, K., J.; Nguewa, P.; Font, M.; Moreno, E.; Espuelas, S.; Jimenez-Ruiz, A.; Palop, J. A.; Plano, D.; Sanmartín, C. Antimicrob. Agents Chemother. 2016, 60, 3802.

(2) (a) Facompre, N. D.; El-Bayoumy, K.; Sun, Y.-W.; Pinto, J. T.; Sinha, R. Cancer Prev. Res. 2010, 3, 975. (b) Sohn, O. S.; Fiala, E. S.; Upadhyaya, P.; Chae, Y. H.; El-Bayoumy, K. Carcinogenesis 1999, 20, 615.

(3) (a) Nikolaienko, P.; Rueping, M. Chem. Eur. J. 2016, 22, 2620. (b) Mukherjee, N.; Kundu, D.; Ranu, B. C. Adv. Synth. Catal. 2017, 359, 329. (c) Maity, P.; Paroi, B.; Ranu, B. C. Org. Lett., 2017, 19, 5748. (d) Krief, A.; Dumont, W.; Delmotte, C. Angew. Chem. Int. Ed. $2000,39,1669$.

(4) (a) Vijay, N.; Anu, A.; Tesmol, G. G. Eur. J. Org. Chem. 2002, 2363. (b) Chen, J.; Wang, T.; Wang, T.; Lin, A.; Yao, H.; Xu, J. Org. Chem. Front. 2017, 4, 130. (c) Muniraj, N.; Dhineshkumar, J.; Prabhu, K. R. ChemistrySelect 2016, 1, 1033. (d) Zhang, H.; Wei, Q.; Wei, S.; Qu, J.; Wang, B. Eur. J. Org. Chem. 2016, $20,3373$.

(5) First synthesis: (a) Verneuil, A. Ann. Chim. Phys. 1886, 41, 328. Crystal data: (b) Aksnes, O., Foss, O. Acta Chem. Scand. 1954, 1787. (c) Hauge, S. Acta Chem. Scand. 1971, 25, 3081. (d) Burchell, C. J.; Kilian, P.; Slawin, A. M. Z.; Woollins, J. D.; Tersago, K.; Van Alsenoy, C.; Blockhuys F. Inorg. Chem. 2006, 45, 710 .

(6) (a) Kachanov, A. V.; Slabko, O. Y.; Baranova, O. V.; Shilova, E. V.; Kaminskii, V. A. Tetrahedron Lett. 2004, 45, 4461. (b) Redon, S.; Obah Kosso, A. R.; Broggi, J.; Vanelle, P. Tetrahedron Lett. 2017, 58, 2771. (c) Redon, S.; Kabri, Y.; Crozet, M. D.; Vanelle, P. Tetrahedron Lett. 2014, 55, 5052.

(7) (a) Reis, J.; Gaspar, A.; Milhazes, N.; Borges, F. J. Med. Chem. 2017, 60, 7941. (b) Gaspar, A.; Matos, M. J.; Garrido, J.; Uriarte, E.; Borges, F. Chem. Rev. 2014, 114, 4960 .

(8) (a) Zhong, S.; Liu, Y.; Cao, X.; Wan, J.-P. ChemCatChem, 2017, 9, 465. (b) Joussot, J.; Schoenfelder, A.; Larquetoux, L.; Nicolas, M.; Suffert, J.; Blond, G. Synthesis 2016, 48, 3364

(9) For similar one-pot procedure from o-hydroxyacetophenone via enaminone species see: Zhang, X.-Z.; Ge, D.-L.; Chen, S.-Y.; Yu X.-Q. RSC Adv., 2016, 6, 66320-66323.

For one-pot procedure from enaminone species see Rafique, J.; Saba, S.; Schneider, A. R.; Franco, M. S.; Silva, S. M., Braga A. L. ACS Omega 2017, 2, 2280-2290.

\section{(10) 3-selenocyanato-4H-chromen-4-ones 3; General procedure}

A mixture of $o$-hydroxyacetophenone $1 \mathrm{a}(136 \mathrm{mg}, 1 \mathrm{mmol}, 1$ equiv.) and dimethylformamide dimethylacetal (120 mg, $1 \mathrm{mmol}, 1$ equiv.) was heated for 2 hours at $100^{\circ} \mathrm{C}$. After cooling to $25^{\circ} \mathrm{C}$, a pre-prepared solution of malononitrile ( $66 \mathrm{mg}, 1 \mathrm{mmol}, 1$ equiv.) and SeO${ }_{2}(332 \mathrm{mg}, 3 \mathrm{mmol}, 3 \mathrm{equiv}$.) in DMSO $(1 \mathrm{~mL})$, stirred at $25^{\circ} \mathrm{C}$ for $20 \mathrm{~min}$, was added at $25^{\circ} \mathrm{C}$. The reaction mixture was stirred for a further $30 \mathrm{~min}$, then water was added ( $\left.3 \mathrm{~mL}\right)$. The resulting precipitate was filtered off, washed with water $(3 \times 10 \mathrm{~mL})$ and dried under a fume hood overnight at $25^{\circ} \mathrm{C}$ to give pure product $3 \mathrm{a}$ 3-selenocyanato-4H-chromen-4-one (3a):

Brown solid, yield: 76\%; mp 136-137 ${ }^{\circ} \mathrm{C} .{ }^{1} \mathrm{H}$ NMR $\left(250 \mathrm{MHz}, \mathrm{CDCl}_{3}\right): \delta=8.26(\mathrm{~s}, 1 \mathrm{H}), 8.20(\mathrm{dd}, J=8.0,1.6 \mathrm{~Hz}, 1 \mathrm{H}), 7.79(\mathrm{dt}, J=8.4,1.7 \mathrm{~Hz}, 1 \mathrm{H}), 7.56(\mathrm{dt}$, $J=8.4 \mathrm{~Hz}, 1 \mathrm{H}), 7.51(\mathrm{dt}, J=7.1,1.1 \mathrm{~Hz}, 1 \mathrm{H}) .{ }^{13} \mathrm{C}$ NMR $\left(62.5 \mathrm{MHz}, \mathrm{CDCl}_{3}\right) \delta \mathrm{ppm} 174.3(\mathrm{CO}), 156.7(\mathrm{C}), 153.1(\mathrm{CH}), 135.1(\mathrm{CH}), 126.5(\mathrm{CH}), 125.9(\mathrm{CH})$, $122.0(\mathrm{C}), 118.6(\mathrm{CH}), 112.7(\mathrm{C}), 100.0(\mathrm{CN})$. HRMS (ESI): $\mathrm{m} / \mathrm{z}$ calcd for $\left[\mathrm{C}_{10} \mathrm{H}_{5} \mathrm{NO}_{2} \mathrm{Se}+\mathrm{H}\right]^{+}:$251.9559, found: 251.9557. 
(11) Redon, S.; Pannecoucke, X.; Franck, X.; Outurquin, F. Org. Biomol. Chem. 2008, 6, 1260.

(12) (a) ten Brink, G.-J.; Vis, J.-M.; Arends, I. W. C. E.; Sheldon, R. A. J. Org. Chem., 2001, 66, 2429. (b) Zhang, X.; Ye, J.; Yu, L.; Shi, X.; Zhang, M.; Xu, Q.; Lautens, M. Adv. Synth. Catal. 2015, 357, 955. 